\title{
Sol-gel synthesis and third-order optical nonlinearity of Au nanoparticles doped monolithic glass
}

\author{
Haihong Gao ${ }^{1}$ - Weidong Xiang ${ }^{1} \cdot \mathrm{Xin}_{\mathrm{Ma}^{1}} \cdot \mathrm{Li} \mathrm{Ma}^{1} \cdot$ Yunyun Huang ${ }^{1} \cdot \mathrm{Huibin} \mathrm{Ni}^{1}$. \\ Xingfei Shi ${ }^{1} \cdot$ Guixiang Chen $^{1} \cdot$ Xiaojuan Liang $^{1}$
}

Published online: 26 November 2015

(C) The Author(s) 2015. This article is published with open access at SpringerLink.com

\begin{abstract}
Gold nanoparticles (Au NPs) doped monolithic and transparent sodium borosilicate glass has been synthesized by both sol-gel and atmosphere control heat treatment methods. Fourier transform infrared (FTIR) spectra in the wavenumber range of 400 to $4000 \mathrm{~cm}^{-1}$ were applied to collect variation information of surface groups of the samples in the sintering process. The microstructure of Au NPs in the glass was characterized by means of X-ray powder diffraction (XRD), transmission electron microscopy (TEM), and high-resolution TEM (HRTEM). Meanwhile, the linear optical properties of the glass were analyzed by UV-vis spectrometer between the wavelength of 300 and $1000 \mathrm{~nm}$, and a broad absorption band around $600 \mathrm{~nm}$ was observed. The third-order nonlinear optical properties of the glass were investigated by using Z-scan technique at the wavelength of $800 \mathrm{~nm}$, pulse duration of $190 \mathrm{fs}$, and repetition rate of $20 \mathrm{~Hz}$. The glass showed saturable absorption and self-focusing nonlinear refraction, and the optical nonlinear susceptibility $\chi^{(3)}$ was estimated to be $1.7 \times 10^{-14}$ esu, with the single-pulse energy of $1 \mu \mathrm{J}$.
\end{abstract}

Keywords Au nanoparticles $\cdot$ Sol-gel $\cdot$ Sodium borosilicate glass $\cdot$ Third-order nonlinearity

Weidong Xiang

xiangweidong001@126.com

$\triangle$ Xiaojuan Liang

1xj6126@126.com

1 College of Chemistry and Materials Engineering, Wenzhou University, Wenzhou 325035, People's Republic of China

\section{Introduction}

To meet the increasing demand of information, new optical and optoelectronic technologies are required, and the ultrafast all-optical switches are considered to play an important role in the next generation broadband optical networks [1-3]. The highly extensive focus and study on nanomaterials in all fields has maintained for decades $[4,5]$. Nanomaterials with great third-order optical nonlinearities and fast response time are significant for future optical device applications [6-8]. Among these nanomaterials that have been studied in the field of nonlinear optics, the metal nanoparticle glasses are regarded as an important candidate of nonlinear optical material. In recent years, many researchers have attempted to introduce various metal nanoparticles into kinds of glasses [9-16]. Au has attracted wide concern over the years, the research on Au can be traced back to the colloidal Au reported in the scientific literature by Faraday in 1857 [17]. As the most stable metal nanoparticles, gold nanoparticles (Au NPs) not only present fascinating aspects such as their assembly of multiple types involving material science, the behavior of the individual particles, size-related electronic, magnetic and unique optical properties but also their applications in nanotechnology, biology, and catalysis, as well as the excellent nonlinear properties and potential prospect in the nonlinear optical devices [12, 18-20]. Particularly, Au NP glasses [18, 21, 22] act as the most widely studied nonlinear material because of the unique plasmon resonance absorption, chemical inertness, and thermal stability. A. I. Ryasnyanskiy et al. [22] synthesized gold nanoparticles embedded in $\mathrm{Al}_{2} \mathrm{O}_{3}, \mathrm{ZnO}$, and $\mathrm{SiO}_{2}$ matrices by radiofrequency magnetron sputtering technique and investigated their third-order nonlinear optical properties by Z-scan method using a frequency-doubled Q-switched $\mathrm{Nd}^{3+}$ :YAG laser (wavelength $532 \mathrm{~nm}$, pulse duration $7 \mathrm{~ns}$, repetition rate $10 \mathrm{~Hz}$ ). The mechanisms responsible for the nonlinear response were discussed, and the temporal analysis results showed the 
prevailing influence of the electronic Kerr effect over the possible thermo-optical contribution. C. Torres-Torres et al. [23] studied the third-order optical nonlinear response of silica composite containing Au NPs and Si-QDs nucleated by ion implantation. The nanocomposites were explored as an integrated configuration containing two different ion-implanted distributions. The ultrafast electronic nonlinearity was associated to the optical Kerr effect for the time-resolved optical Kerr gate and Z-scan techniques $(825 \mathrm{~nm}, 80 \mathrm{fs})$, while a thermal effect was identified as the main mechanism responsible for the nonlinear optical refraction induced by nanosecond pulses ( $532 \mathrm{~nm}, 1 \mathrm{~ns})$. Abeer Salah et al. [24] synthesized Au and Au-CdSe nanoparticles (NPs) at different NP sizes and concentrations by organometallic pyrolysis method and they conducted OA Z-scan measurements by a Q-switched Nd-YAG laser (532 nm, $6 \mathrm{ns)}$ ) as a function of excitation energy. The result showed that the location of SP energy and excitonic peak shifted from 538 to $613 \mathrm{~nm}$ as the NP size increased and saturation absorption was reversed by increasing power densities. S. Tamil Selvan et al. [25] reported the sol-gel-derived gold/silica glasses and test the third-order optical nonlinearities by a degenerate four-wave mixing (DFWM) technique (20 ns), the test showed that the gold/silica glasses exhibit large third-order nonlinear optical susceptibilities.

Among the various substrates, borosilicate glass demonstrates the unique superiority. To the best of our knowledge, borosilicate glass has low thermal expansion coefficient and high chemical durability, which render borosilicate glass good resistance to thermal shock and breaking [26, 27]. The stable physical and chemical properties make borosilicate glass widely used in modern laboratory equipment and optical devices. Since the first small pieces of transparent borosilicate glass prepared by sol-gel process by Dislich in 1971, many glass researchers tried to make bulk silica glasses and multi-component glasses by sol-gel method [28]. Prior to other preparation methods such as deposition [29] and melt quenching [30], the borosilicate glass prepared by sol-gel approach possesses eminent advantages such as good transparency, low formation temperature, significant phase transition, and uniformity of the doping components [31]. Therefore, borosilicate glass is considered a competent base glass to load metal nanoparticles or quantum dots and potential candidate for optoelectronic devices [10]. What is more, the transition process from solution to gel then to sodium borosilicate glass has been studied systematically [32-37] by the Fourier transform infrared (FTIR), nuclear magnetic resonance (NMR), hermogravimetry and differential thermal analysis (TG-DTA), and Brunauer-Emmett-Teller (BET) analysis, and the results show that the high temperature thermal saturation, appropriate atmosphere control and heat treatment together contribute greatly to the formation of doped nanoparticles or quantum dots, and the shrinkage of several nanometer porous structured stiff gel into well-densified glass material, with the glass transition temperature between 519 and $565^{\circ} \mathrm{C}$.
About two decades ago, we synthesized 0.124 wt.\% Au glass by sintering $\mathrm{Au}$ doped sodium borosilicate bulk gel [38], but the characterization was limited by the low doping concentration and the test conditions at that time. With the help of modern advanced characterization methods and the keen interest in $\mathrm{Au}$ glass, combined with the present research situation of sodium borosilicate glass, we choose $600{ }^{\circ} \mathrm{C}$ as the sintering temperature. Herein, we present a typical sol-gel synthesis of Au nanoparticles doped monolithic and transparent sodium borosilicate glass, and this study mainly focuses on the synthesis, microstructure, and optical properties of the $\mathrm{Au}$ NPs glass. The obtained glass was characterized by the FTIR, X-ray powder diffraction (XRD), transmission electron microscopy (TEM), high-resolution transmission electron microscopy (HRTEM), selected area electron diffraction (SAED), UV-vis, and Z-scan technology.

\section{Experimental details}

\section{Materials}

Tetraethoxysilane $\left(\left(\mathrm{Si}\left(\mathrm{OC}_{2} \mathrm{H}_{5}\right)_{4}\right.\right.$, TEOS, AR $\left.)\right)$, hydrochloric acid ( $\mathrm{HCl}, \mathrm{AR})$, boric acid $\left(\mathrm{H}_{3} \mathrm{BO}_{3}, \mathrm{AR}\right)$, metallic sodium (Na, 99.7\%), 2-methoxyethanol $\left(\mathrm{C}_{3} \mathrm{H}_{8} \mathrm{O}_{2}, \mathrm{AR}\right)$, chloroauric acid hydrated $\left(\mathrm{HAuCl}_{4} \cdot 4 \mathrm{H}_{2} \mathrm{O}, 99.99 \%\right)$, and anhydrous ethanol $\left(\mathrm{C}_{2} \mathrm{H}_{5} \mathrm{OH}, \mathrm{AR}\right)$ were purchased from Aladdin Chemistry Co., Ltd, Shanghai, China. All chemicals were used directly without any further purification, except that the $\mathrm{pH}$ value of the hydrochloric acid was adjusted to about 2 by adding deionized water.

\section{Synthesis procedure}

The $5 \mathrm{Na}_{2} \mathrm{O}-20 \mathrm{~B}_{2} \mathrm{O}_{3}-75 \mathrm{SiO}_{2}$ (in wt.\%) containing glass doped with $0.25 \mathrm{wt} . \% \mathrm{Au}$ NPs was fabricated by combining a typical sol-gel method and subsequent heat treatment process, and the procedure was as follows:

1. The formation of glass precursor solution. Firstly, TEOS was hydrolyzed at room temperature in anhydrous ethanol using $\mathrm{HCl}(\mathrm{pH}=2)$ as catalyst to form $\mathrm{SiO}_{2}$ component. Secondly, the other two precursor solutions, $\mathrm{H}_{3} \mathrm{BO}_{3}$ powder dissolved in $\mathrm{C}_{3} \mathrm{H}_{8} \mathrm{O}_{2}$ and metallic $\mathrm{Na}$ dissolved in $\mathrm{C}_{2} \mathrm{H}_{5} \mathrm{OH}$, were added into the well-hydrolyzed TEOS solution in sequence to form $\mathrm{B}_{2} \mathrm{O}_{3}$ and $\mathrm{Na}_{2} \mathrm{O}$ components. After the above solution was continuously stirred for $1 \mathrm{~h}$ at room temperature, an ethanol solution of $\mathrm{HAuCl}_{4}$. $4 \mathrm{H}_{2} \mathrm{O}$ was added to form $\mathrm{Au}$ nanoparticles. All these chemicals were added according to the designed glass composition. At last, the mixed solution was decanted into plastic boxes and placed steadily at room temperature for later gelation. 
2. The formation of stiff gel. After the above solution was placed for 1 week, wet gel was formed, as shown in Fig. 1a. Then, the wet gel in the boxes were dried in the vacuum oven at $80^{\circ} \mathrm{C}$ for about 3 weeks to form the stiff gel, shown in Fig. 1c.

3. The transition of stiff gel to glass. The stiff gel was heat treated in tube furnace by the program controlled heating process: Firstly, the stiff gel was heated in oxygen $\left(\mathrm{O}_{2}\right)$ atmosphere at the heating rate of $5{ }^{\circ} \mathrm{C} \mathrm{h}^{-1}$ from room temperature to $450{ }^{\circ} \mathrm{C}$ (the slow heating rate can effectively avoid crush and fragmentation of the stiff gel) and kept for $5 \mathrm{~h}$ at $450{ }^{\circ} \mathrm{C}$ to remove the residual organic solvent and to decompose $\mathrm{HAuCl}_{4} \cdot 4 \mathrm{H}_{2} \mathrm{O}$. Secondly, the stiff gel was exposed to high-purity hydrogen $\left(\mathrm{H}_{2}, 99.99 \%\right)$ at $450{ }^{\circ} \mathrm{C}$ for $5 \mathrm{~h}$ to form metallic $\mathrm{Au}$. Finally, the loose and porous stiff gel was heated in nitrogen $\left(\mathrm{N}_{2}\right)$ atmosphere at a heating rate of $10{ }^{\circ} \mathrm{C} \mathrm{h}^{-1}$ from 450 to $600{ }^{\circ} \mathrm{C}$, and kept for $2 \mathrm{~h}$ at $600{ }^{\circ} \mathrm{C}$ for densification. At last, the light brown and monolithic $\mathrm{Na}_{2} \mathrm{O}-\mathrm{B}_{2} \mathrm{O}_{3}-\mathrm{SiO}_{2}$ glass containing $\mathrm{Au}$ NPs was obtained. The glass sample was cut and polished as shown in Fig. 1d.
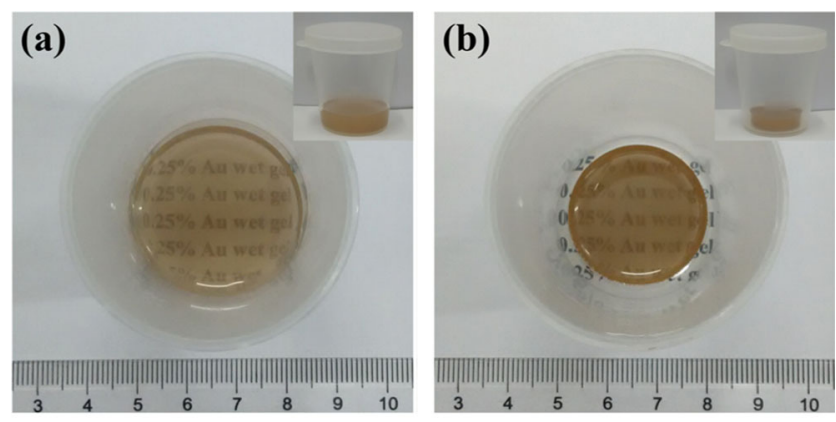

(c)
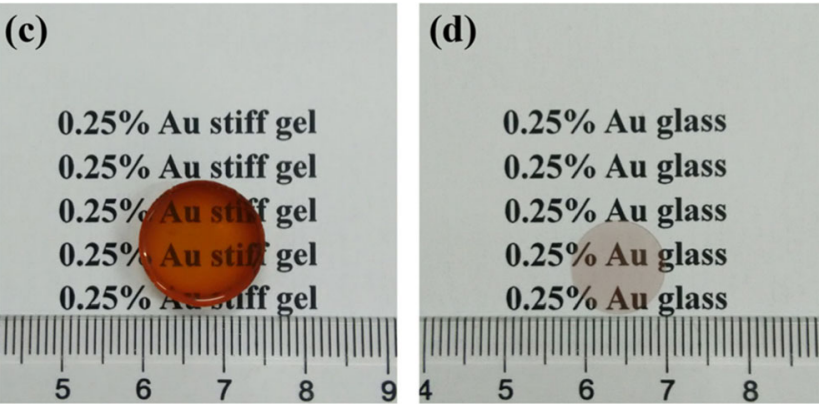

Fig. 1 Samples in the preparation procedure: a $0.25 \%$ Au wet gel in the box (seen from above, solution placed for 1 week, with size $34 \mathrm{~mm}$ in diameter, $9 \mathrm{~mm}$ in thickness $(34 \times 9 \mathrm{~mm})$. Inset shows the photo seen from the side.), b $0.25 \%$ Au aged wet gel (solution placed for 4 weeks at room temperature, with size $28 \times 6 \mathrm{~mm}$. Inset shows the photo seen from the side.), c $0.25 \%$ Au stiff gel (solution placed for 1 week, and dried at $80{ }^{\circ} \mathrm{C}$ for 3 weeks in the vacuum oven, with size $15 \times 3.5 \mathrm{~mm}$ ), and $\mathbf{d}$ polished $0.25 \% \mathrm{Au}$ glass (heat treated, cut, and polished sample, with size $11 \times 0.2 \mathrm{~mm}$ )

\section{Characterization}

The Bruke Equinox 55 FTIR spectrometer was used to obtain the Fourier transform infrared (FTIR) spectra, the xerogel samples were grounded with $\mathrm{KBr}$ power and were measured in the wavenumber range of 400 to $4000 \mathrm{~cm}^{-1}$ at room temperature. X-ray diffraction analysis of the polished transparent glass was applied on a Germany Bruker X-ray diffractometer (XRD, $40 \mathrm{kV}, 20 \mathrm{~mA})$ using $\mathrm{Cu} \mathrm{Ka}$ radiation $(\lambda=$ $0.15418 \mathrm{~nm}$ ) at the scan rate of $0.02^{\circ} \mathrm{s}^{-1}$ in the $2 \theta$ range $15^{\circ}$ to $85^{\circ}$. Transmission electron microscopy (TEM) for imaging of morphology and direct determination of nanocrystal size of Au NPs, high-resolution TEM (HRTEM), and selected area electron diffraction (SAED) images for further analysis of the Au NPs were carried out on an FEI Tecnai F-20 transmission electron microscope operating at $200 \mathrm{kV}$. The sample for TEM was prepared by crushing the glass into powder with agate mortar and pestle, a drop of the ethanol powder suspension was placed onto the carbon-coated holey copper grid followed by drying at room temperature. The linear optical absorption and transmission of the glass sample in the wavelength range of 300-1000 nm was collected at room temperature by a Perkin Elmer Lambda 750 UV-vis spectrometer. The open aperture and closed aperture Z-scan tests of the glass were carried out at the wavelength of $800 \mathrm{~nm}$, the repetition rate of $20 \mathrm{~Hz}$, pulse width of $190 \mathrm{fs}$, and single-pulse energy of $1 \mu \mathrm{J}$.

\section{Results and discussion}

\section{FTIR studies}

The FTIR spectra were collected to get the detailed structural groups information of samples obtained at different processing temperatures $\left(100,200,300,400,500\right.$, and $\left.600{ }^{\circ} \mathrm{C}\right)$, as shown in Fig. 2. The obvious variation of surface groups of the samples is reflected in the range of 3340 to $3670 \mathrm{~cm}^{-1}$. The sharp band $\left(3593 \mathrm{~cm}^{-1}\right)$ of the sample treated at $100{ }^{\circ} \mathrm{C}$ should be attributed to the $-\mathrm{OH}$ stretching vibration of free water [39], and it is broadened and blue shifted to $3666 \mathrm{~cm}^{-1}$ as the temperature reaches to $200{ }^{\circ} \mathrm{C}$. The band $\left(3363 \mathrm{~cm}^{-1}\right)$ of the $100{ }^{\circ} \mathrm{C}$ sample should be attributed to the $-\mathrm{OH}$ stretching vibration of the intermolecular association bond [40], and it is broadened and red shifted to $3344 \mathrm{~cm}^{-1}$ as the temperature reaches to $200{ }^{\circ} \mathrm{C}$. Further increase of the temperature, the predominant $-\mathrm{OH}$ stretching vibration band $\left(3448 \mathrm{~cm}^{-1}\right)$ becomes weak due to the dehydration of $-\mathrm{OH}$ band and the removal of water, suggesting the decrease of the $\mathrm{Si}-\mathrm{OH}$ bond and hydrogen bond (2984 and $2926 \mathrm{~cm}^{-1}$ ) [41], hydrogen-bonded $\mathrm{OH}$ stretching vibrations $\left(2368 \mathrm{~cm}^{-1}\right)$, and typical vibration of $\mathrm{H}_{2} \mathrm{O}\left(1642 \mathrm{~cm}^{-1}\right)$ [42] and the increase of B-O stretching vibration $\left(1403 \mathrm{~cm}^{-1}\right), \mathrm{B}-\mathrm{O}-\mathrm{B}$ symmetric 


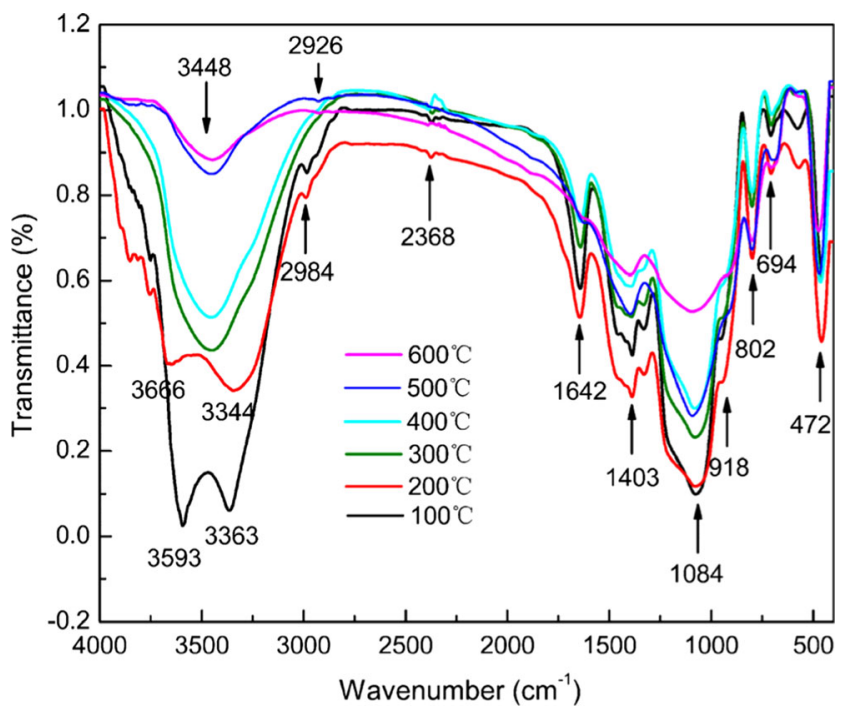

Fig. 2 FTIR spectra of the xerogel sintered at different temperatures $\left(100,200,300,400,500\right.$, and $\left.600{ }^{\circ} \mathrm{C}\right)$

stretching band $\left(802 \mathrm{~cm}^{-1}\right)$ [42], bending vibrations of bridging oxygen (BO) between triagonal BO3 groups $\left(694 \mathrm{~cm}^{-1}\right)$ [43], Si-O-Si stretching vibration $\left(1084 \mathrm{~cm}^{-1}, 802 \mathrm{~cm}^{-1}\right)$ [39], Si-O-B vibration band $\left(918 \mathrm{~cm}^{-1}\right)$ [42], and $\mathrm{Si}-\mathrm{O}-\mathrm{Si}$ bending vibration band $\left(472 \mathrm{~cm}^{-1}\right)$ [43] in the samples, thus the stable glass network structure forms as the sintering temperature increases, accompanied with a series of chemical reactions such as dehydration, dealcoholization, and deetherization.

\section{XRD studies}

To explore whether Au nanocrystals had formed in the transparent glass, X-ray diffraction measurement was performed. The XRD pattern of the glass sample is presented in Fig. 3. The broad bag-like amorphous diffraction peak in the range of $18^{\circ}$ to $25^{\circ}$ is caused by the base glass diffraction, which is the characteristic peak of sodium borosilicate glass substrate [34]. The sharp diffraction peak located at $2 \theta=38.18^{\circ}$ represents (111) crystal plane of the face-centered cubic-structured $\mathrm{Au}$ crystalline, and the four relatively small peaks located at $44.39^{\circ}, 64.58^{\circ}, 77.55^{\circ}$, and $81.72^{\circ}$ can represent the (200), (220), (311), and (222) crystal planes of Au crystalline, respectively. The lattice constant calculated from the above is $a=2.36 \AA$, which is in accordance with the standard data from JCPDS Card No. 04-0784 ( $a=2.3548 \AA$ ). No other peaks are detected in the XRD pattern, demonstrating that high purity of the Au nanocrystals have formed in the sodium borosilicate glass substrate.

The average size of Au nanoparticles is estimated by the following Scherrer formula [44]:

$d=\frac{K \lambda}{\beta \cos \theta}$

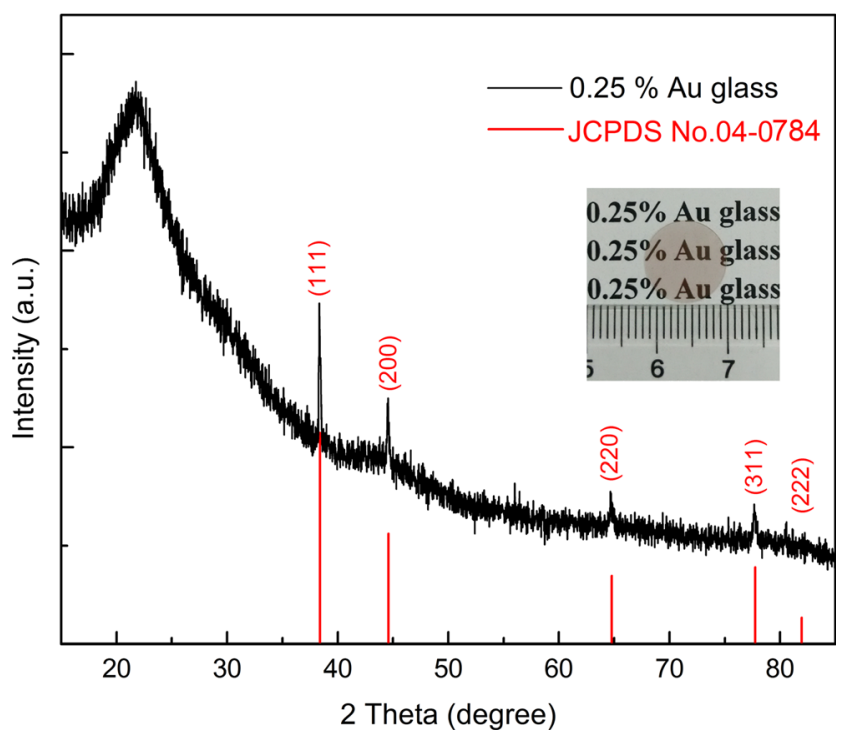

Fig. 3 XRD patterns of the 0.25 wt.\% Au glass

$d$ represents the average particle size of Au nanocrystals, $\lambda$ stands for X-ray wavelength, $\beta$ for half peak width (FWHM), $\theta$ for Bragg diffraction angle, and $\mathrm{K}$ was approximately 0.9 . We calculate the average particle size of Au nanocrystals in the glass to be $5.7 \mathrm{~nm}$. To verify the XRD results and analysis, TEM was applied subsequently.

\section{TEM studies}

TEM, HRTEM, and SAED were applied to further study the morphology and microstructure of the glass sample. Figure 4a shows the TEM image of the sample, from which we can see

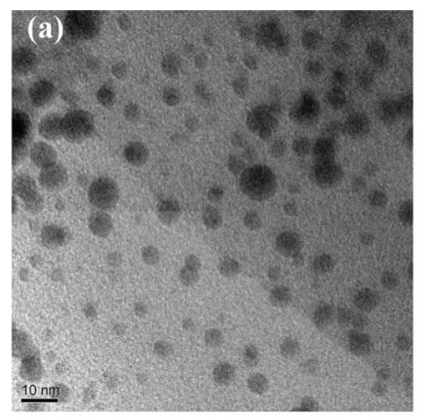

(b)
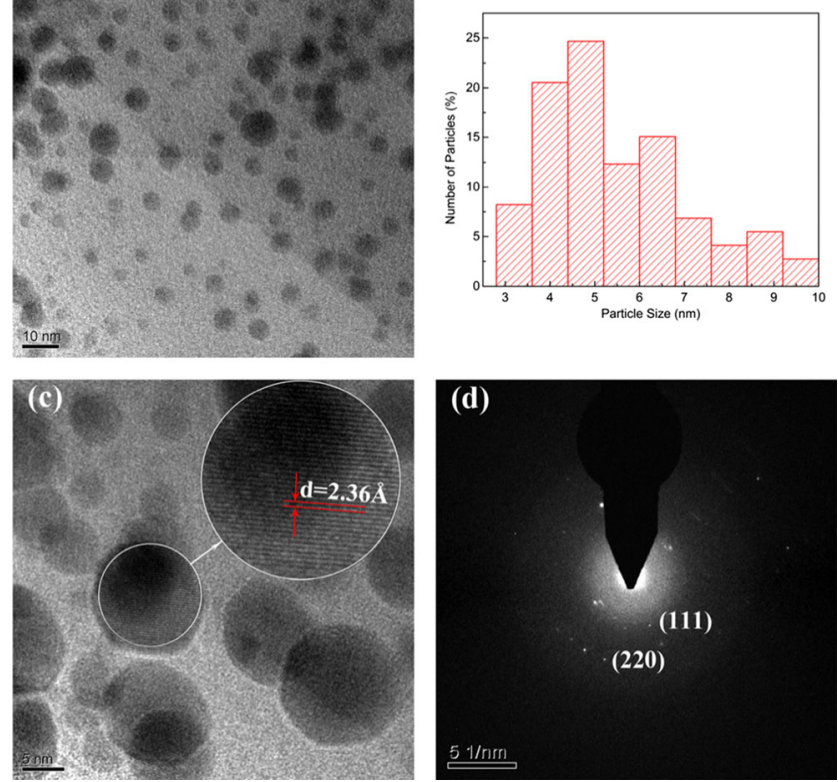

Fig. 4 TEM images of the glass: a TEM morphology image, $\mathbf{b}$ particle size distribution image, c HRTEM image, and d SAED image 


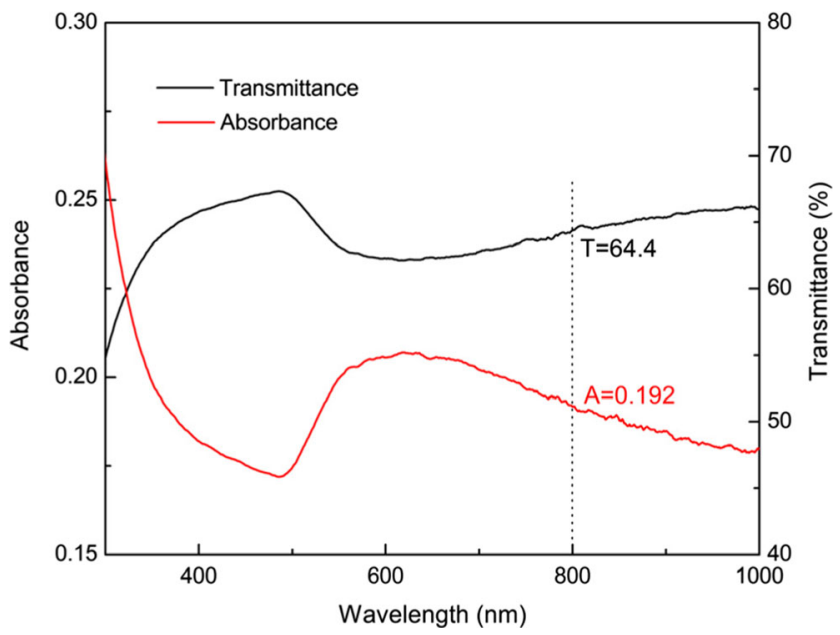

Fig. 5 The absorption (in red line) and transmission (in black line) spectra of the Au glass

that there are lots of black spherical dots dispersed in the gray glass substrate background. The particle size ranges from 2.82 to $9.97 \mathrm{~nm}$, with an average size of $5.48 \mathrm{~nm}$, which is in good agreement with the XRD calculation, as shown in Fig. 4b. Figure $4 \mathrm{c}$ shows the HRTEM image of the nanoparticles in the glass. The crystal plane spacing is measured to be $2.36 \AA$, close to the lattice parameter of Au cubic structure (PDF\#04-0784, $2.355 \AA$ for (111) plane). Figure $4 d$ is the SAED image, in which the relatively obvious diffraction rings are assigned to $\mathrm{Au}$ (111) and (220) diffraction planes. These results are in good accordance with the XRD analysis. Both the XRD and TEM analyses confirm that cubic Au nanocrystals have formed in the sodium borosilicate glass matrix.

\section{UV-vis studies}

As an empirical judgment of whether the material is available to the Z-scan test or not, the linear absorption and transmission were tested between the wavelength of 300 and $1000 \mathrm{~nm}$. Figure 4 displays the absorption and transmission spectra of the Au NPs doped glass. The broad absorption band around $600 \mathrm{~nm}$ was observed for the sample in Fig. 5. As is known, size, concentration and spacing of particles, solvent dielectric constant, substrate matrix, and variations of initial chemical compositions $[45,46]$ influence the optical response of metal particles materials. The typical spectra of Au nanoparticles appear at $520 \mathrm{~nm}$ [20], which originates from the surface plasma resonance absorption. The broad absorption band around $600 \mathrm{~nm}$ shows obvious red shift compared with the typical spectra, but still similar to the values reported for $\mathrm{Au}$ particles in the literature [20,47]. The red shift of the broad surface plasma resonance absorption and the brown color could be the formation of larger nanoparticles coupling to surface plasmons in glass matrix and the superposition of multiple absorption peaks [20, 46-48]. The linear absorbance and transmittance values at the wavelength of $800 \mathrm{~nm}$ were tested to be 0.192 and $64.4 \%$; the relatively small absorption could minimize the test errors in the Z-scan test.

\section{Nonlinear optical properties studies}

As a simple, highly sensitive, single-beam experimental technique for determining the sign and magnitude of the nonlinear refraction and nonlinear absorption [49], the Z-scan technique is a popular method for testing optical nonlinearities. To determine the nonlinear absorption and refraction of the Au NPs doped sodium borosilicate glass sample, open aperture (OA) and closed aperture (CA) Z-scan measurements were carried out. Figure 6 displays open aperture $(S=1)$ and closed aperture $(S=0.05) \mathrm{Z}$-scan results with single-pulse energy of $1 \mu \mathrm{J}$. Here, the black dots in the figure indicate the experimental data while the red solid line for theoretical fit of the normalized transmittance. The OA Z-scan curve of the glass sample in Fig. 6a is symmetric relative to the focus $(Z=0)$ where it had maximum transmittance of the glass, suggesting saturable absorption [35] will occur in the glass. The CA Z-scan model shown in Fig. $6 \mathrm{~b}$ with pre-focal $(Z<0)$ minimum and the post-focal $(Z>0)$ maximum indicates a self-focusing process $[10]$ and a positive sign of nonlinear refractive index $(\gamma>0)$. The nonlinear absorption coefficient $(\beta)$ and nonlinear refractive index $(\gamma)$ of the glass are fitted and calculated from the $\mathrm{OA}$ and CA Z-scan tests according to the Sheikbahae's well-known theory [50].
Fig. 6 a Z-scan curve of the open aperture and $\mathbf{b} Z$-scan curve of the closed aperture (experimental data in black dots; theoretical curve in red line)
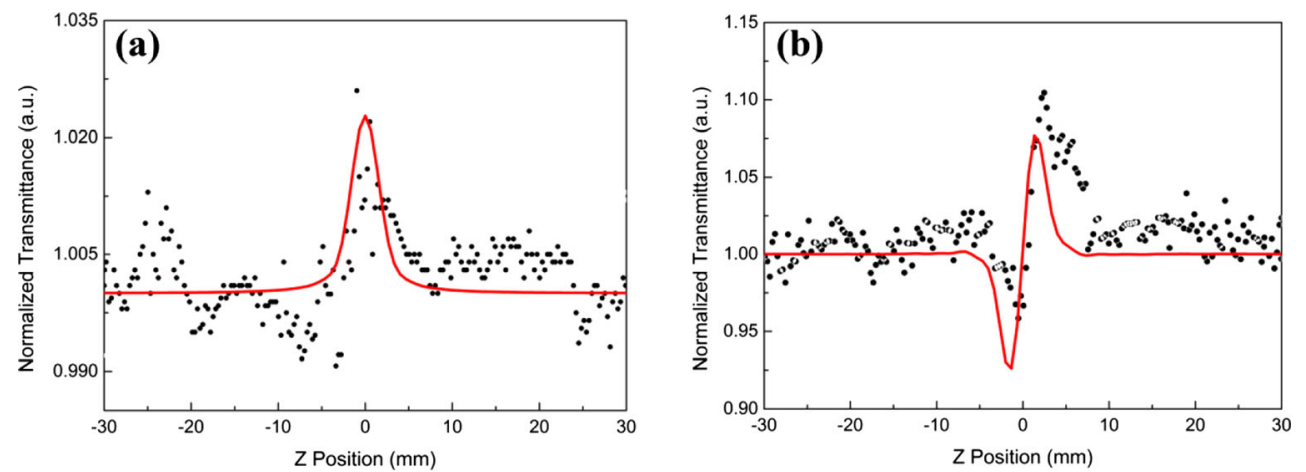
Table 1 The third-order nonlinear optical parameters of the Au doped glass at $800 \mathrm{~nm}$ with single-pulse energy of $1 \mu \mathrm{J}$

\begin{tabular}{lllll}
\hline Parameters & $\beta(\mathrm{m} / \mathrm{w})$ & $\operatorname{Im} \chi^{(3)}(\mathrm{esu})$ & $\gamma\left(\mathrm{m}^{2} / \mathrm{w}\right)$ & $\operatorname{Re} \chi^{(3)}(\mathrm{esu})$ \\
\hline Data & $-6.5 \times 10^{-14}$ & $-2.3 \times 10^{-15}$ & $3.0 \times 10^{-20}$ & $1.6 \times 10^{-14}$ \\
\hline
\end{tabular}

The nonlinear optical absorption data obtained under the condition in this study can be described by Eqs. (2) and (3) [51].

$T(z)=\frac{1}{\sqrt{\pi q(z)}} \int_{-\infty}^{\infty} \ln [1+q(z)] e^{-\tau^{2}} d \tau$

$q(z)=I(z) \frac{1-e^{-\alpha_{0} L}}{\alpha_{0}} \beta$

where $\alpha_{0}$ and $\beta$ are linear and effective third-order nonlinear optical absorption coefficients, $\tau$ is the response time, and $L$ is the thickness of the sample. Light transmittance $(T)$ and irradiation intensity $(I)$ are two functions of the sample's $Z$ position (with respect to the focal position at $Z=0$ ).

The nonlinear refraction $Z$-scan curve was obtained by dividing CA Z-scan data and corresponding OA Z-scan data. An effective third-order nonlinear optical refractive index $\gamma$ can be derived by Eqs. (4) and (5) [52].

$$
\begin{aligned}
& \Delta T_{p^{-v}}=0.406(1-S)^{0.25}\left|\Delta \varphi_{0}\right| \\
& \Delta \varphi_{0}=(2 \pi / \lambda) \frac{1-e^{-\alpha_{0} L}}{\alpha_{0}} \gamma I_{0}
\end{aligned}
$$

where the $\Delta T_{p^{-v}}$ is the difference between normalized transmittance values at peak and valley portions, taken from the CA Z-scan curve in Fig. 5b. $I_{0}$ is the pulse irradiation intensity at the focus, which is calculated by the single-pulse energy, and $\lambda$ is the wavelength of the laser.

The calculated $\beta$ and $\gamma$ values are applied to deduce the real and imaginary part of the third-order nonlinear susceptibility according to Eqs. (6) and (7) [53].

$$
\begin{aligned}
& \operatorname{Im} \chi^{(3)}(\mathrm{esu})=\frac{\lambda \varepsilon_{0} c^{2} n_{0}^{2}}{4 \pi^{2}} \beta(m / W) \\
& \operatorname{Re\chi } \chi^{(3)}(\mathrm{esu})=\frac{\varepsilon_{0} c^{2} n_{0}^{2}}{\pi} \gamma\left(m^{2} / W\right)
\end{aligned}
$$

where $\lambda, \varepsilon_{0}, c$, and $n_{0}$ represent the wavelength of the laser light, permittivity of free space, speed of light, and linear refractive index of the glass, respectively. The absolute value of optical third-order nonlinear susceptibility $\chi^{(3)}$ is given by Eq. (8) [54].

$$
\left|\chi^{(3)}\right|(\mathrm{esu})=\left\{\left(\operatorname{Re} \chi^{(3)}\right)^{2}+\left(\operatorname{Im} \chi^{(3)}\right)^{2}\right\}^{\frac{1}{2}}
$$

All of the nonlinear parameters are listed in Table 1. The third-order nonlinear absorption was saturable, and the third-order nonlinear susceptibility reached $1.7 \times 10^{-14}$ esu.

\section{Conclusions}

In conclusion, the monolithic and transparent $\mathrm{Au}$ NPs doped sodium borosilicate glass has been successfully synthesized by combining the typical sol-gel method and atmosphere control heat treatment process. The FTIR analysis revealed the variation of structural groups of samples obtained at different temperatures, clarifying the formation process of the stable glass network structure as the sintering temperature increases. The XRD and TEM analyses revealed the formation of face-centered cubic Au nanocrystals in the sodium borosilicate glass matrix, with particle size ranging from 2.82 to $9.97 \mathrm{~nm}$ and an average size of $5.48 \mathrm{~nm}$. The molecular level introduction of $\mathrm{Au}$ precursor and effective control of heat treatment contribute greatly to the successful synthesis of Au nanoparticles doped glass. The UV-vis analysis showed a broad absorption band around $600 \mathrm{~nm}$, showing obvious red shift compared with the typical spectra. In addition, the nonlinear optical properties of the obtained glass were determined at the near infrared wavelength of $800 \mathrm{~nm}$ using Z-scan technology, the results indicated that the Au NPs doped glass showed saturable absorption and nonlinear refractive index with self-focusing process with the single-pulse energy of $1 \mu \mathrm{J}$. The nonlinear absorption coefficient $\beta$ and the nonlinear refraction index $\gamma$ were calculated to be $-6.5 \times 10^{-14} \mathrm{~m} / \mathrm{w}$ and $3.0 \times 10^{-20} \mathrm{~m}^{2} / \mathrm{w}$, the third-order nonlinear susceptibility of the glass sample was estimated to be $\chi^{(3)}=1.7 \times 10^{-14}$ esu. As the estimated nonlinear optical properties are affected by many factors such as nanoparticle size and concentration, laser power, and repetition rate of lasers [22, 24], this study paves the way for more detailed researches in the future. With further improvement, the glass may have potential application in nonlinear optics.

Acknowledgments The authors acknowledge financial support from the National Nature Science Foundation of China (51272059, 51472183, and 51172165).

Open Access This article is distributed under the terms of the Creative Commons Attribution 4.0 International License (http://creativecommons. org/licenses/by/4.0/), which permits unrestricted use, distribution, and reproduction in any medium, provided you give appropriate credit to the original author(s) and the source, provide a link to the Creative Commons license, and indicate if changes were made. 


\section{References}

1. Miller DAB (2010) Nat Photonics 4:3-5

2. Volz T, Reinhard A, Winger M, Badolato A, Hennessy KJ, Hu EL, Imamoğlu A (2012) Nat Photonics 6:605-609

3. Li W, Chen BG, Meng C, Fang W, Xiao Y, Li XY, Hu ZF, Xu YX, Tong LM, Wang HQ, Liu WT, Bao JM, Shen YR (2014) Nano Lett 14:955-959

4. Lin GM, Shang M, Zhang WG (2014) Adv Mater Res 912:305308

5. Zhong JS, Chen DQ, Zhao WG, Zhou Y, Yu H, Chen LF, Ji ZG (2015) J Mater Chem C 3:4500-4510

6. Erasmus M, Cason ED, van Marwijk J, Botes E, Gericke M, van Heerden E (2014) Gold Bull 47:245-253

7. Medhi, Nandi P, Mohan S, Jose G (2007) Mater Lett 61:2259-2261

8. Chen WL, Beck KM, Bücker R, Gullans M, Lukin MD, TanjiSuzuki H, Vuletić V (2013) Science 341:768-770

9. Liu QM, He X, Zhou X, Feng R, Xiao XH, Jiang CZ, Zhou H, Zhao XJ, Lu LP, Qian SX (2011) J Non-Crystal Solids 357:2320-2323

10. Zhong JS, Xiang WD, Zhao HJ, Zhao WG, Chen GX, Liang XJ (2012) J Alloys Compd 537:269-274

11. Dousti MR, Sahar MR, Amjad RJ, Ghoshal SK, Awang A (2013) J Lumin 143:368-373

12. Chen FF, Dai SX, Xu TF, Shen X, Lin CG, Nie QH, Liu C, Heo J (2011) Chem Phys Lett 514:79-82

13. Stepanov AL, Galyautdinov MF, Evlyukhin AB, Nuzhdin VI, Valeev VF, Osin YN, Evlyukhin EA, Kiyan R, Kavetskyy TS, Chichkov BN (2013) Appl Phys Lett 111:261-264

14. Srivastava SK, Gangopadhyay P, Amirthapandian S, Sairam TN, Basub J, Panigrahia BK, Nair KGM (2014) Chem Phys Lett 607: 100-104

15. Karvonen L, Rönn J, Kujala S, Chen Y, Tervonen A, Svirko Y, Honkanen S (2013) Opt Mater 36:328-332

16. Toda I, Tsuruoka T, Matsui J, Murashima T, Nawafune H, Akamatsu K (2014) RSC Adv 4:4723-4726

17. Liz-Marzán LM (2004) Mater Today 7:26-31

18. Aziz MA, Kim JP, Shaikh MN, Oyama M, Bakare FO, Yamani ZH (2015) Gold Bull 48:85-92

19. Ramakrishna P, Prabin P, Muralikrishna M, Adarsh K, Sai M, Siva Sankara SS, Ramaprabhu S, Apparao R (2015) Opt Mater 39:182187

20. Daniel MC, Astruc D (2004) Chem Rev 104:293-346

21. Wu D, Tang XH, Yoon HS (2015) J Nanoparticle Res 17:1-8

22. Ryasnyanskiy AI, Palpant B, Debrus S, Pal U, Stepanov A (2007) J Lumin 127:181-185

23. Torres-Torres C, López-Suárez A, Can-Uc B, Rangel-Rojo R, Tamayo-Rivera L, Oliver A (2015) Nanotechnology 26:295701295708

24. Salah A, Mansour A, Mohamed MB, Azzouz IM, Elnaby S, Badr Y (2015) Appl Surf Sci 353:112-117

25. Selvan ST, Hayakawa T, Nogami M, Kobayashi Y, Liz-Marzán LM, Hamanaka Y, Nakamura A (2002) J Phys Chem B 106: $10157-10162$

26. Axinte E (2011) Mater Des 32:1717-1732

27. Forde LC, Proud WG, Walley SM, Church PD, Cullis IG (2010) Int J Impact Eng 37:568-578
28. Sakka S (2005) Springer Science \& Business Media, Inc., New York, pp 129-148

29. de la Garza M, Hernández T, Colás R, Gómez I (2010) Mater Sci Eng B 174:9-12

30. Zhang R, Lin H, Yu YL, Chen DQ, Xu J, Wang YS (2014) Laser Photonics Rev 8:158-164

31. Pei L, Xiang WD, Zhao XL, Liang XJ, Yang XY, Liu HT, Chen ZP, Xie CP, Ma X, Zhang CL, Ma L, Zhao JL (2014) Mater Res Bull 59:154-161

32. Xiang WD, Wang ZC, Yang QZ, Zhao WX, Wang CY, Ding ZS, Weng WJ (1996) J Mater Sci Technol 12:303-306

33. Zhong JS, Ma X, Lu HW, Wang X, Zhang SL, Xiang WD (2014) J Alloys Compd 607:177-182

34. Zhong JS, Zhao HJ, Zhang CL, Ma X, Pei L, Liang XJ, Xiang WD (2014) J Alloys Compd 610:392-398

35. Zhong JS, Xiang WD, Zhao HJ, Chen ZP, Liang XJ, Zhao WG, Chen GX (2012) Mater Res Bull 47:3691-3696

36. Zhang CL, Xiang WD, Luo HY, Liu HT, Liang XJ, Ma X, Pei L, Chen ZP, Li JS, Gao HH, Ma L (2014) J Alloys Compd 602:221227

37. Xiang WD, Zhao HJ, Zhong JS, Yang XY, Guo YQ, Luo HY, Liang XJ (2012) J Am Ceram Soc 95:1588-1594

38. Xiang WD, Wang CY, Wang ZC, Yang QZ, Zhao WX, Ding ZS, Wang ML, Wang JH (1996) Acta Opt Sin 16:967-971

39. Marzouk SY, Seoudi R, Said DA, Mabrouk MS (2013) Opt Mater 35:2077-2084

40. Xie JX, Chang JB, Wang XM (2001) Science Press, Beijing, pp 298-301

41. Saad EA, ElBatal FH, Fayad AM, Moustafa FA (2011) Silicon 3: 85-95

42. Efimov AM, Pogareva VG (2000) J Non-Cryst Solids 275:189-198

43. Rao TGVM, Kumar AR, Neeraja K, Veeraiah N, Reddy MR (2013) J Alloys Compd 557:209-217

44. Patterson A (1939) Phys Rev 56:978-982

45. Gurin VS, Alexeenko AA, Zolotovskaya SA, Yumashev KV (2006) Mater Sci Eng C 26:952-955

46. Malikova N, Pastoriza-Santos I, Schierhorn M, Kotov NA, LizMarzán LM (2002) Langmuir 18:3694-3697

47. Linnik OP, Zhukovskiy MA, Starukh GN, Smirnova NP, Gaponenko NV, Asharif AM, Khoroshko LS, Borisenko VE (2015) J Appl Spectrosc 81:990-995

48. Huang T, Murray RW (2001) J Phys Chem B 105:12498-12502

49. Huang HH, Yan FQ, Kek YM, Chew CH, Xu GQ, Ji W, Oh PS, Tang SH (1997) Langmuir 13:172-175

50. Sheik-Bahae M, Said AA, Wei TH, Hagan DJ, Van Stryland EW, Wei TH (1990) IEEE J Quantum Electron 26:760-769

51. Chen SH, Li YJ, Yang WL, Chen N, Liu HB, Li YL (2010) J Phys Chem C 114:15109-15115

52. Qu SL, Song YL, Du CM, Wang YX, Gao YC, Liu ST, Li YL, Zhu DB (2001) Opt Commun 196:317-323

53. Fan GH, Ren ST, Qu SL, Guo ZY, Wang Q, Wang YS, Gao RX (2013) Opt Commun 295:219-225

54. Wang YH, Wang YM, Lu JD, Ji LL, Zang RG, Wang RW (2010) Opt Commun 283:486-489 